\title{
Tango: la ficción y la Argentina portátil.
}

\section{Tango: Fiction and the Portable Argentina.}

\section{Resumen}

Este artículo se centra en un caso temprano del Hispanismo transnacional: la figura del escritor español Vicente Blasco-Ibáñez, que viajó a la Argentina en 1909, escribió una novela con personajes argentinos (Los cuatro jinetes del Apocalipsis, 1916) y fue internacionalmente reconocido por la película basada en la novela (1921). La película se filmó en Los Angeles, donde comenzó la "Blascomanía". Rodolfo Valentino, vestido de gaucho, bailó el tango y pronto comenzó la "fiebre del tango". El escritor global y la industria cinematográfica global desarrollaron nuevos territorios argentinos en el mercado global de la cultura.

Palabras claves

Ciudad, neoliberalismo, consumos culturales, Buenos Aires.

\begin{abstract}
This essay is focused on an early case of Transnational Hispanism: the figure of the Spanish writer Vicente Blasco-Ibáñez, who traveled through Argentina in 1909, wrote a novel with Argentine characters (The Four Horsemen of Apocalypse, 1916) and was internationally acclaimed for a movie based on his novel (1921). The movie was shot in Los Angeles where "Blascomania" begun Rodolfo Valentino, in a gaucho dressing, danced tango and started "tango fever." Global writer and global film industry developed new Argentinian territories in the global market of culture.
\end{abstract}

Keywords

Tango, Valentino, Blasco Ibáñez, Representation, Argentina.

En 1921 se estrena uno de los grandes éxitos de cine mudo, Los cuatro jinetes del Apocalipsis. La película, dirigida por Rex Ingram, dura 123 minutos y 
la protagoniza un joven Rodolfo Valentino, que se consagrará como estrella precisamente con esta actuación. Valentino será el protagonista de una historia antibélica y moralizante, la adaptación al cine hecha en Hollywood de una novela muy exitosa del español Vicente Blasco Ibáñez. Esta película, en donde Valentino baila el tango para el mundo entero, significó la consagración de muchas cosas, de Valentino, como dijimos, pero también del tango y de Blasco Ibáñez como escritor de éxito internacional. Quisiera revisar la historia detrás de una película exitosa y las tramas que cruzan cultura, mercado, identidad, y estética a comienzos del siglo XX en un espacio que ya es definitivamente transnacional y transatlántico, antes y después de su estreno. La producción de esta película conjuga, en Hollywood, muchas de las tensiones de época: la guerra europea, la internacionalización de los intelectuales, la relación de la cultura letrada con el mercado, la exotización de las identidades y la creciente globalización de la producción estética. Conjuga una territorialidad localizada que, sin embargo, la ficción -literaria y cinematográfica- convierte en escenario cuando la pone a circular en el mercado global. Me interesa estudiar este film cuya trama comienza con inmigrantes europeos en Argentina, continúa con inmegrantes argentinos en Europa y fue filmada y producida en Los Angeles, un lugar donde esas tradiciones diferentes pudieron combinarse. Todas estas tradiciones fueron alteradas por los nuevos contextos a que se expusieron. Los Angeles fue la tercera parte de un triángulo en el que la cultura de España, América Latina y Estados Unidos cruzaron sus caminos. Allí, las comunidades hispanas tuvieron que ejerecr múltiples negociaciones para poder establecer sus propios lugares y desplazamientos.

El film sigue casi puntualmente la trama de Los cuatro jinetes del Apocalipsis, que Blasco Ibáñez publicó en 1916 en París, en español. ${ }^{1}$ Esta novela fue escrita por encargo del presidente francés, Raymond Poincaré que gobernó Francia entre 1913 y 1920. En el prólogo a la edición de 1923 de esta historia

\footnotetext{
${ }^{1}$ Una crítica que recibió la película fue que tenía "mucho texto" para hacer avanzar la acción, lo que se hizo necesario porque la trama de la novela está llena de episodios y personajes.
} 
antibélica, profrancesa pero cuyo protagonista es un argentino "típico", Blasco Ibáñez cuenta que Poincaré, le pidió: “-Quiero que vaya usted al frente -me dijo-, pero no para escribir en los periódicos. Eso pueden hacerlo muchos. Vaya como novelista. Observe, y tal vez de su viaje nazca un libro que sirva a nuestra causa." (Blasco Ibáñez 6). Y el escritor fue: "Nunca trabajé en peores condiciones. Tuve las manos y el rostro agrietados por el frío; usé zapatos y calcetines de combatiente, para sufrir menos los rigores del invierno" (7). Los sufrimientos no le impidieron escribir por encargo esta novela de propaganda antibélica que le pidió el presidente francés en un paisaje argentino primero, luego con argentinos que viajan a Europa. Su novela se convirtió en un éxito en pocos años a través de la recepción que tuvo en Europa y, sobre todo, en Estados Unidos, se tradujo muy rápidamente a varios idiomas y terminó de consagrarse con el éxito de la película.

La trama es enrevesada y compleja, como si quisiera poner todos los conflictos del momento sobre la mesa para que su mensaje propagandístico sea explícito: es la historia de una familia de estancieros de Argentina. La familia fue fundada por un inmigrante español que se enriqueció con el negocio del ganado, que casó a sus dos hijas con maridos europeos, un francés y un alemán, y tuvo varios nietos, entre los cuales Julio Desnoyers (hijo de padre francés) es el preferido. Cuando muere el abuelo, las familias viajan a Europa. En París, Julio, que es un "bueno para nada", gasta su fortuna en fiestas y mujeres y se convierte en un galán y en eximio bailarín de tango. Hasta aquí se trata de una novela típica de Blasco, que combina el realismo con el costumbrismo. Pero comienza la guerra (el encargo de Poincaré) y aparece el relato moralizante y la propaganda a que se había comprometido: surge en el ambiente bélico el sentimiento nacionalista y Julio, que es un bon vivant y extranjero, sigue enamorando mujeres, sin comprometerse con la tragedia de su tiempo, tiene un affaire con una mujer casada que, aunque lo ama, lo abandona para acompañar a las tropas como enfermera y seguir a su marido a la guerra. Descolocado, totalmente fuera de lugar, Julio sufre una crisis y se enrola en el ejército francés (se reconcilia así con la tradición paterna), lucha a favor de los "ideales franceses" y muere defendiendo 
la libertad. Este melodrama tenía todos los elementos para atraer al público masivo en 1916 y aunque no fue un éxito inmediato en España pronto la traducción le permitió volverse un éxito en Europa y América. Lo decisivo para su éxito fue la edición en inglés. En Estados Unidos se convirtió muy rápidamente en uno de los libros más leídos y fue el libro más vendido en Estados Unidos en 1919 según Publishers Weekly. ${ }^{2}$ Esa traducción fue fundamental en la historia de Blasco, según cuenta su biógrafo, Ramiro Reig:

Desde julio de 1918, en que apareció, a mediados del año siguiente las ventas habían ido creciendo hasta alcanzar la increíble cifra de trescientos mil ejemplares. El primer sorprendido debió ser el mismo Blasco que había vendido los derechos de autor por mil dólares, renunciando al porcentaje de ventas, seguramente porque pensaba que iban a ser inferiores a lo cobrado. El editor le envió generosamente una compensación de veinte mil dólares $\mathrm{y}$, de sorpresa en sorpresa, recibió una invitación para una gira de conferencias por Estados Unidos. El éxito de la novela había suscitado por todo el país una de esas olas a las que los americanos son tan aficionados, la blascomanía. Se vendían corbatas, pañuelos, ceniceros, pisapapeles, con imágenes de Los cuatro jinetes, y los incontables lectores estaban ansiosos por conocer al autor. (Reig 186-7)

Blasco fue, desde sus comienzos, un escritor interesado en el mercado, que siempre estuvo atento a sacar provecho de su escritura a través de los intereses del nuevo público; fue uno de los primeros escritores modernos en español cuyos

\footnotetext{
${ }^{2}$ Su éxito es muy sorprendente. Blasco Ibáñez se vuelve una celebridad en Estados Unidos, viaja por todo el país dando conferencias, e incluso recibe el doctorado honoris causa de la Universidad de Washington. Ramiro Reig dice que llega a cobrar mil dólares por artículo. También dice que al regresar a Europa Blasco se compró un Rolls Royce.
} 
libros se convirtieron en best-seller y que escribió para el público masivo ${ }^{3}$. Él manejaba sus propios intereses, ocupándose de la edición de sus proyectos. Completamente involucrado con los procedimientos de la cultura de masas y de la industria cultural del momento, Blasco Ibáñez encontró en el sistema de los estudios de Hollywood su contraparte. Su deseo de hacer dinero apelando a las grandes audiencias internacionales encontró satisfacción cuando llegó a Los Angeles.

La comunidad hispana de la ciudad tenía un importante periódico en español, El Heraldo de México, que cubrió la visita y el éxito de Blasco Ibáñez. Pero el periodismo de todo el país dio cuenta de su tour de conferencias, de costa a costa, que dio gracias al éxito de la traducción de Los cuatro jinetes del Apocalipsis, a principios de los años veinte. Los periódicos locales informaban su arribo a la ciudad, sus conferencias, sus opiniones sobre el país y las costumbres, e incluso informaban sobre su salud. El éxito de Blasco se vive con orgullo en las comunidades hispanas aunque se vuelve controversial cuando las opiniones políticas de Blasco se vuelven abiertamente pro-americanas. Pero, en general, la recepción de su visita fue muy entusiasta entre el público masivo.

Blasco Ibáñez ya era muy conocido como escritor. Aunque muchos de sus colegas se resistían a reconocer sus valores literarios, tuvo gran éxito de mercado. Sus novelas se concentran en el argumento (simple pero con intrigas enrevesadas, personajes típicos y ambientes locales) a la vez que su estilo trata de ser completamente legible, lejos de toda sofisticación. Quizás por esto, Blasco no discute las adaptaciones de sus novelas en los estudios de Hollywood. Por otro lado, el éxito inesperado de su primera novela deja a Blasco en una posición débil para negociar con los grandes agentes de las editoriales y los estudios americanos:

\footnotetext{
${ }^{3}$ Dice Reig que en 1914 proyecta editar una Historia de la guerra europea. "Constaría de ciento cincuenta a doscientos fascículos que saldrían semanalmente al precio de cincuenta céntimos, y cada fascículo tendría treinta y dos páginas. Con grabados en cada una de ellas y una gran lámina central. La tirada sería de veinte mil ejemplares... Presentó un plan de los primeros fascículos, partiendo del asesinato de Sarajevo, pero luego fue metiendo todo lo que se le ocurría al hilo de los acontecimientos; los frentes de guerra, la vida en la retaguardia, las ambulancias, las enfermeras, los generales, las trincheras, los gases asfixiantes, el cañón Berta, los submarinos, en fin, todo lo imaginable" (172). Salieron varios capítulos de ese proyecto.
} 
había vendido los derechos de traducción de Los cuatro jinetes por 1.000 dólares y había renunciado al porcentaje de ventas pensando que la novela no iba a tener grandes ventas y que ese adelanto no las iba a cubrir. Después del gran éxito de ventas, el editor le "regala" 20.000 dólares. Pero la gran retribución es la invitación a hacer un tour de conferencias por todo el país. Consigue además un encargo para escribir en periódicos. Blasco aprendió muy rápidamente a sacar provecho de su ambigua identidad (europeo para él pero "hispano" para los americanos) y navegó la doble zona oceánica con destreza: explotó su autoridad europea para hablar del mundo hispano.

A diferencia de sus proyectos literarios (en los que él escribía, editaba, publicaba y publicitaba sus propias obras), la historia de la filmación de las películas es más compleja pues involucra a mucha gente. En el caso de Los cuatro jinetes, "It began with a novel. Richard Rowland, the president of Metro, was following with fascination the mounting circulation figures for Vicente Blasco Ibáñez's latest book, The Four Horsemen of the Apocalypse. It was, in today's language, a literary blockbuster" (Barton 72). Poco a poco aparecen los demás personajes de este éxito: June Mathis, quien escribe el guión y probablemente sugiere la contratación de Rex Ingram como director y de Rodolfo Valentino como protagonista. Filmada en Hollywood, la historia de Blasco adquiere una nueva forma en la ya compleja trama de relaciones transnacionales. Según refiere Ruth Barton, "Like Rex, she [Mathis] was fascinated by the exotic qualities of ancient civilizations, although she took this further than he did, believing that she had once been an Egyptian and that Rex, along with her other new discovery, Rudolph Valentino, had in this previous life been her sons" (Barton 75). Menos que la verdad de esta historia, me interesan sus resonancias. Esa "fascinación" de Mathis e Ingram por lo exótico alcanza, muy concretamente, la representación de lo argentino, que es el escenario de una de las escenas centrales de la película (centrales no por su peso en la trama sino por su impacto en el público): Valentino (que es Julio, el protagonista ingenuo y seductor) bailando el tango en un cabaret 
de los arrabales de Buenos Aires junto a su abuelo. Los dos estarán vestidos de gaucho.

Pero Blasco Ibáñez no interviene en la producción del film. Su inteligencia y experticia residían en su capacidad para manejar y administrar su propia imagen y su fama literaria así que él no tuvo problemas en delegar el complejo sistema de hacer la película en los expertos de Hollywood. Lo más importante es que los estudios de Hollywood había encontrado una nueva historia exótica con muchos personajes exóticos. Se trataba, en efecto, de una trama exótica, pero no tanto en una ciudad como Los Angeles, de creciente población hispana. La película representó un desafío para los productores: cómo representar a los refinados y urbanos personajes hispanos y mostrarlos como exóticos y realistas al mismo tiempo. En la ficción, los europeos y los latinoamericanos pertenecen a diferentes niveles; si los alemanes y franceses tienen los roles dramáticos (como patriotas y soldados), los argentinos se muestran como exóticos y despreocupados (bailarines y "Latin lovers"). Valentino jugó un papel fundamental como personaje "exótico" en sí mismo, para representar otro tipo de exotismo.

\section{Exotizando Argentina, pero también México}

Vicente Blasco Ibáñez viaja a la Argentina en 1909 para un tour de conferencias. Como otros "invitados ilustres" Blasco llega al país en los comienzos de las celebraciones del Centenario de la revolución de independencia. Por esa época, a un empresario teatral, Faustino Da Rosa, se le ocurre la idea de contratar a intelectuales europeos para hacer pequeñas giras culturales, en los teatros de Buenos Aires, donde los espectáculos estaban creciendo al ritmo de la cultura masiva. Da Rosa había llevado al país anteriormente a Jean Jaurés, 
Clemenceau y otras personalidades ${ }^{4}$. Blasco Ibáñez recibió el trato de una verdadera celebridad. En su mayoría son inmigrantes españoles quienes sostienen al escritor quien prolonga su estadía por nueve meses, dando conferencias por una vasta geografía sudamericana que incluye Buenos Aires, el interior de Argentina, Paraguay y Chile. Sus conferencias son otra forma de acrecentar su público y aumentar su popularidad. Su amigo Emilio Gascó Contell testimonia:

Innecesario será decir que una campaña oratoria de tan considerable magnitud, realizada en semejantes condiciones, carecía en absoluto de preparación, y que las improvisaciones eran las más de las veces el producto virgen de la facundia imaginativa. Cualquier tema local o nacional, nacional o exterior, político o puramente artístico, constituía para aquellos públicos una oración apasionante. El propio Blasco me refería muchos años más tarde - y con ello confirmaba ingenuamente el fondo de parecido que conservaba la cruel caricatura del viejo France—que a su llegada a cualquier ciudad nueva se enteraba por los periódicos o por las autoridades del tema sobre el cual deseaban que disertase. Con frecuencia le señalaban un asunto de interés local. Y entonces, unas simples lecturas técnicas, una rápida información bastaban al orador para estar hablando aquella misma noche durante hora y media..., pero sin aburrir jamás al auditorio. (Gascó Contell 141)

\footnotetext{
${ }^{4}$ Según Reig, Blasco Ibáñez había conocido en París, en casa de su amante chilena Elena Ortúzar, a Bartolomé Mitre (director de La Nación de Buenos Aires, periódico en el que ya colaboraba) y al Director del Banco Español del Río de la Plata. Ambos lo invitan a conocer el país y hacer una gira para dar conferencias. Probablemente a través de alguno de ellos se haya hecho el contacto con Da Rosa.
} 
La improvisación sobre temas locales es la clave del éxito. ${ }^{5} \mathrm{Y}$ las conferencias son la escena perfecta para conquistar al público que luego irá a comprar el periódico que las reproduce y luego sus libros. Blasco Ibáñez encuentra en Argentina un buen lugar para su ego y también para su economía pues, convertido en celebridad, gana mucho dinero. Sin embargo, surgirán pronto los problemas. A medida que va conociendo el interior del país, varios inversores lo entusiasman con la idea de comprar y explotar tierras trayendo colonos valencianos. Pone manos a la obra llevando adelante así una empresa colonizadora. Para hacerlo, se endeudó por años y hubo acusaciones de corrupción y fraude de Blasco y algunos funcionarios argentinos que prometieron ayudarlo con las colonias. Dice Blasco de este episodio de su vida:

El ensueño de hacerme millonario, aunque no fuese más que por una temporada; la perspectiva de mandar en un ejército de trabajadores, de transformar el aspecto de un rincón del mundo, de crear lugares habitables en el desierto, eran visiones demasiado brillantes para que no aceptase correr los riesgos de una empresa tan gigantesca. (Gascó Contell 144)

Sus sueños imperiales se desvanecen porque pierde el dinero que invirtió (los préstamos de bancos provinciales), se endeuda pues no tuvo en cuenta la cambiante situación económica del país y no planificó las inversiones necesarias para que las secas tierras de la provincia de Río Negro rindieran, ni para que las de Corrientes pudieran convertirse en verdaderas colonias.

\footnotetext{
${ }^{5}$ La primera conferencia en el teatro Odeón, abarrotado de público según los testimonios, fue "América vista desde España" como consigna Ramiro Reig en su biografía. Le siguieron "La leyenda negra de España" y "Las grandes figuras del descubrimiento". Luego continuó con Balzac, Victor Hugo y Zola. Llevó estos temas al interior del país y, de vuelta en Buenos Aires, se animó con Cervantes, Lope de Vega, la novela del siglo XIX, para terminar con exposiciones sobre Velázquez, Goya y El Greco.
} 
Regresará a Europa. Sin embargo, antes tuvo tiempo de componer el monumental La Argentina y sus grandezas, libro de setecientas sesenta y ocho páginas, editado en cuarto mayor, con ilustraciones; el libro es una descripción más que entusiasta de las ventajas económicas del país (escrito a principios de 1909 el libro se publica en Madrid en julio de 1910). ${ }^{6}$ Libro también escrito por encargo, parecía el cierre de su ciclo argentino, donde todo había terminado en fracaso.

Pero la Argentina retorna a través de la novela que le encarga el presidente francés. En ella, Blasco Ibáñez condensa varios estereotipos de la Argentina: los estancieros argentinos que dilapidan fortunas en Europa, los "niños bien" que sobresalen en París bailando tango y enamorando muchachas, la barbarie del campo argentino. Con todos ellos Blasco triunfa en Europa y escribe su novela por encargo. Es una ficción que está escrita para el público europeo y que explota el exotismo y lo melodramático de una historia de amor interrumpida por la guerra. La película, en cambio, fue hecha para un público internacional y crea otros estereotipos ${ }^{7}$. En los estudios de la Metro, principalmente el productor Marcus Loew, sintieron temor de que la película cayera mal en algunos sectores pero también que no fuera el éxito que esperaban por su final trágico. Por eso, se filmó un final feliz y varias escenas tienen dobles versiones. Según Barton, "It also means that different audiences across the globe saw quite different versions of the film" (Barton 79).

En 1921, la película atrae al público ya relajado de la inmediata posguerra, con sus caracteres exóticos pero que se convierten a través del melodrama en

\footnotetext{
${ }^{6}$ El libro es un gran escrito de divulgación y propaganda del país, con extensas descripciones geográficas y las posibilidades de explotación de los recursos naturales. Abunda en fotos de todo tipo, en muchas de las cuales se lo ve al propio Blasco posando entre indígenas y gauchos, con aires semejantes a los modernos emprendedores-colonizadores.

7 The four horsemen of the Apocalyse, como la novela, es un alegato pro-francés y fuertemente anti alemán. En la propaganda antibélica, Blasco Ibáñez es muy enfático en denostar todo lo que tenga que ver con Alemania de manera muy poco sutil (el tío alemán de Julio y sus sobrinos nacionalistas, son caricaturescos). A su vez, por su fin moralizante, Julio muere al final, sacrificando su vida por "el país de la libertad", el de su padre.
} 
ejemplos morales. ${ }^{8}$ Rex Ingram era conocido por su obsesión en reconstruir ambientes. En el set de filmación tenía expertos en historia militar francesa y alemana para cuidar todos los detalles de las batallas y de la puesta en escena de la guerra y el comportamiento de los militares así como sus uniformes y armas. Lo mismo hizo con la reconstrucción de los interiores. ¿Qué pasa con la representación de lo más exótico de este film, lo argentino? ${ }^{9}$

En la nota del New York Times comentando la película el domingo 27 de marzo de 1921, a toda página (10 y continúa en 13), señala su autor, John Corbix, que "Since the truth must be told, the first part of the performance, wich begins in Argentina and brings the characters to France and to the verge of the war, is not very deeply interesting, in spite of the excellence of the acting and the amazing prodigality of the production" (Corbix 10). Después de señalar que se ha gastado mucho dinero en esta película, la conclusión es que, "In retrospect, far more than when the war was on, "The Four Horsemen" is allied propaganda" (10).

La escena más famosa de esta película sobre la guerra es, como dijimos, aquella en la Valentino baila tango. ¿Por qué el énfasis en el color local? ¿Solo para que se luzca Valentino? ${ }^{10}$ La escena no aparece en la novela, pero resulta muy potente en el cine. El contraste entre lo urbano y lo rural (las vestimentas de gaucho de los personajes, en un cabaret ubicado en un subsuelo por cuyas ventanas superiores se ve gente que camina por una calle iluminada), entre la sensualidad del baile y la violencia masculina asociada al tango y los bajos

\footnotetext{
${ }^{8}$ La contracara de este éxito llegará en 1962, cuando se filma una nueva versión -muy libre- de la novela de Blasco, ambientada en la segunda guerra mundial, con Glenn Ford e Ingrid Thulin en los papeles centrales. A diferencia de la primera, fue un fracaso comercial y de crítica. La película de Ingram se hizo en momento adecuado, cuando la guerra que recién había terminado parecía la última y el sacrificio por la libertad parecía tener sentido. En 1962, en plena guerra fría, un Julio Desnoyers seductor y políticamente ingenuo ya no tiene sentido (tampoco Glenn Ford da para ese rol).

${ }^{9}$ De acuerdo con Cynthia Tompkins, son más de veinte las películas filmadas en Hollywood con tema argentino en los años 20; entre ellas Los cuatro jinetes del apocalipsis, Good Men and Bad (1923), Argentina Lose, A Sainted Devil (1924), The Temptress (1926 con Greta Garbo), The Gaucho (1927). Santos Goñi, attache cultural de la Embajada argentina en San Francisco, funcionaba como un consejero para estereotipos argentinos.

${ }^{10}$ Recordemos que Valentino había hecho papeles menores hasta entonces, que es con esta película que se consagra y se consolida su imagen de Latin Lover.
} 
fondos, termina de atraer la atención hacia ese ambiente de exotismo y barbarie. El escenario, las ropas de los personajes, las conductas, todo se concentró para producir una escena artificiosa que llamó la atención del público. Compuesta en Hollywood resultó absolutamente verosímil para el público y se convirtió en modelo tanto de lo gaucho como del tango.

A Blasco, que había cobrado su dinero, nada de esto le importaba mucho y no intervino en el guión. Por el contrario se olvida de Argentina pero se relaciona con otra zona donde explotar estereotipos. Aprovechando su estadía en Estados Unidos, viaja a México para ver de cerca la revolución, con el proyecto de escribir una novela (titulada, previsiblemente, El Águila y la serpiente, que nunca se publicó). Allí es huésped de otro presidente, Venustiano Carranza, líder revolucionario. En un confuso episodio, pero cuyo rumor él hace circular, en la cena oficial con el presidente le roban su valioso reloj. Es solo uno de los muchos detalles en una visita que creó gran cantidad de sonados conflictos. Carranza es destituido mientras Blasco está en México y se suceden una serie de nuevos eventos revolucionarios que hacen que el escritor regrese a Estados Unidos. En New York, es contratado por uno de los principales grupos editoriales para que "explique" la revolución mexicana, que ha vivido -por poco tiempo- en el lugar de los hechos. Otra escritura por encargo. Sus artículos para el New York Times y el Chicago Tribune son muy leídos y reproducidos en todo el país. Ellos se vuelven controversiales porque en México los consideran una ofensa nacional, una intromisión en asuntos domésticos y una forma de validar la intervención americana en suelo mexicano. Dos libros recopilan las notas de Blasco: Artículos sobre México (publicado en México en 1920, con prólogo de Enrique del Llano) y El militarismo mexicano (del mismo año, publicado en Valencia por el mismo Blasco). En el prólogo del primero, del Llano denuncia la traición y contradicciones de Blasco al escribir sobre México para los diarios de Estados Unidos; en el prólogo del segundo, Blasco -en un extenso descargo fechado en París en 1920- explica que quiere reproducir los artículos publicados en diarios americanos para demostrar que solo describe cómo la revolución se convirtió en 
militarismo. Blasco nunca podrá volver a México pues la relación con el país y sus intelectuales nunca mejoró. Blasco cobró cada palabra que escribió sobre Argentina y cada palabra que escribió sobre México. En el escenario global que se le abrió con la guerra y la industria del cine, cobró además por el derecho a las imágenes. La respuesta mexicana no vino solo de los intelectuales. En 941, Cantinflas, el célebre actor cómico mexicano, protagonizó "Ni sangre ni arena," una parodia de "Blood and Sand," película también de 1941 protagonizada por Tyrone Power y Rita Hayworth, basada en una novela de Blasco. Con epicentro en Hollywood se crearon para Estados Unidos y para el mundo versiones que canonizaron imágenes de América Latina.

Pero la máquina de producir identidades era una calle de doble vía. Poco después de su regreso a Europa, en 1923, Blasco publicó una nueva novela en Valencia, España, titulada La reina Calafia (traducida al inglés en 1924). En otra enrevesada trama, la novela cuenta la historia de un conjunto de personajes transatlánticos. El principal es una californiana (de raíces mexicanas) envuelta en un romance con un joven español (nacido en México), hijo de su primer amor. Calafia es el sobrenombre de Mrs. Douglas (Concha Ceballos de soltera), una poderosa y autosuficiente viuda que representa el estereotipo tanto de sus raíces mexicanas como de la moderna mujer americana ${ }^{11}$. California y su pasado se incorporan como material ficcional para presentar al público europeo y latinoamericano las idas y vueltas de la experiencia transnacional. Esta vez, Blasco aprendió la lección; en el copyright leemos que todos los derechos (de reproducción, traducción y adaptación) pertenecen a Vicente Blasco Ibáñez.

Los estereotipos, sin embargo, tienen una existencia doble. Dos décadas después del primer gran éxito de Blasco en Hollywood, los mexicanos irán por su revancha. En 1941 Cantinflas protagoniza Ni sangre ni arena, una parodia de la película del mismo año, Neither Blood nor Sand, basada en la novela Sangre y

11 Blasco apela a un prestigioso antecedente literario para este sobrenombre, Las sergas de Esplandián, de Garci Rodríguez de Montalvo, una novela de caballerías de 1751 que cuenta la historia de la conquista de California por conquistadores españoles. 
Arena de Blasco, de 1908, protagonizada por Tyrone Power y Rita Hayworth. La película de Cantiflas fue un gran éxito en América Latina y entre la población hispana de California.

\section{El tango}

Ninguna película se reduce a una escena; sin embargo, hay escenas que pueden definir completamente a una película. Eso pasó con aquella en la que Valentino baila el tango en Los cuatro jinetes. Según las fuentes, Valentino había pedido explícitamente que haya una escena de baile cuando se enteró de que tendría el papel: "Valentino's first success came in a small but widely noticed role in the hit Eyes of Youth, directed by Albert Parker and released in 1919. Hearing that Four Horsemen was being cast, he wondered if there might be a dancing part for him on the production" (Barton 76). No se equivocó al pedir la escena, que fue ampliamente celebrada en todo el mundo y lo convirtió en el latin lover para siempre.

En París, el tango argentino, desde 1913 se había convertido en una "fiebre" que atacó a las clases altas y bohemias de la ciudad. En Argentina el tango surgió en las zonas marginales de la ciudad de Buenos Aires a fines del siglo XIX y tuvo una trayectoria ambigua: fue una música y una danza despreciada socialmente pero que los jóvenes ricos aprendieron a bailar clandestinamente, en los prostíbulos del margen urbano. Según algunas versiones, esos jóvenes llevaron la danza a París y otras ciudades de Europa, al mismo tiempo que, por la difusión de espectáculos transnacionales, algunos músicos de tango viajaron a España y Francia. Lo cierto es que el tango llega a Europa en la primera década del siglo $\mathrm{XX}$ por varias vías. Y rápidamente es adoptado por las clases altas aunque en Argentina seguía siendo una música prohibida y de los bajos fondos. Es por esta razón que Rodríguez Larreta, jefe de la legación 
argentina en París, prohibe que se baile en la sede diplomática y dice que es un baile de burdeles. Por la misma época, corrió el rumor (nunca confirmado oficialmente pero de gran efecto) de que el papa Pío X habría prohibido bailar el tango por tratarse de una danza pornográfica. Por otro lado, Jean Richepin, alaba el tango en su discurso de ingreso a la Academie Francaise e incluso escribe, junto con su esposa, una comedia en cuatro actos, titulada "El tango." Sin duda, el tango fue un éxito en Europa y también en Estados Unidos (donde había muchos profesores de danza que lo enseñaban a bailar). Será a partir de ese éxito internacional que regresa a Argentina como una danza más decente, que puede ser bailada en público después que ha triunfado en las capitales del mundo moderno.

El tango fue, desde su inicio, una danza urbana, que se bailaba en las calles de Buenos Aires. Y sin embargo la consagración del tango en la escena global fija el estereotipo del músico y cantante de tango vestido de gaucho. Francisco Canaro aporta, en sus memorias, una información sustancial cuando relata su primer viaje a París en 1925 y la dificultad que inicialmente tuvieron para poder tocar con la orquesta en lugares públicos:

[...] en virtud de una ley que protegía al "Sindicato de Músicos" perteneciente a la "Unión de Combatientes", muchos de los cuales eran mutilados de guerra. Las orquestas extranjeras solo podían actuar como "orquesta de atracción" justificando una característica especial que denotase una novedad específica. Y, ante este dilema, cambiamos impresiones con el señor Lombart para colocarnos dentro de las disposiciones vigentes. Se nos ocurrió entonces, vestir a toda la orquesta de gauchos e introducir en nuestros programas algunos recitados buscando la manera de hacer algo que nos diferenciara de las demás orquestas; a este efecto utilicé interesantes fragmentos de "Martín Fierro" que yo me sabía de memoria, y una circunstancia providencial vino a reforzar nuestros planes. Resulta que uno de mis violinistas, 
Ferrazzano, de contrabando y sin que yo me enterase, había embarcado con él a su compañera, que era una chica llamada Asprela, que cantaba tangos y canciones vestida de gaucho y acompañándose con su guitarra. (Canaro 98-99)

Por las consecuencias de la guerra entonces, el tango, para sobrevivir, debe "disfrazarse" y obedecer las directivas del sindicato de músicos profesionales. La ocurrencia de vestir de gauchos a los músicos, surgida de la necesidad de continuar con el espectáculo, se institucionaliza rápidamente. Francisco García Jiménez, cuando recuerda a la actriz y cancionista Linda Thelma, dice que ella, que antes de la primera guerra mundial actuó en Europa y que cantaba temas de Villoldo, "Vestía de hombre, modalidad flamante para una cantora, que Azucena Maizani repetiría veinte años después. De gaucho o compadrito, según la canción” (47). El vestido gaucho del tango en París no es sino recurso ante las demandas muy concretas de la industria cultural y las regulaciones políticas en la Francia de la posguerra; para poder actuar en París, había que disfrazar el tango de argentino. Canaro dice haber impuesto lo que se convirtió en una moda que aseguraba el éxito de las orquestas de tango:

A partir del debut de mi orquesta en el dancing "Florida", el público parisién no concibió en lo sucesivo la presentación de orquestas argentinas cuyos componentes no estuvieran ataviados con la vestimenta gaucha, que era, por así decirlo, la legítima expresión simbólica de nuestra carta de ciudadanía criolla. (102)

Independizado de la Argentina, el tango se convierte en un bien de consumo de las elites internacionales. Es también Canaro quien recuerda que 
Una noche que caminaba por una de las calles de París, vi venir en dirección a mí a un gaucho muy bien empilchado con su traje típico, y al acercarse se me ocurrió decirle en tono campero: “¡Güenas noches, paisano!” [...] Y el tipo que iba con un violín debajo del brazo, me contestó el saludo con un "Bonsoir, monsieur”. Era un músico francés disfrazado de gaucho. (Canaro 109)

La sorpresa no lo hace escarmentar, pocos meses después la escena se repetirá con un director de orquesta de tangos en un lugar elegante de Berlín; el director y sus músicos tocaban vestidos de gauchos, pero eran alemanes. Canaro usa la palabra "disfraz" para describir su concepción mimética de lo nacional. ${ }^{12}$ Desde entonces, el tango, ya institucionalizado, siguió un largo camino de transformaciones e identificó lo nacional en la mixtura del gaucho con la música urbana.

De acuerdo con Sergio Pujol y Girogio Betellini, el éxito de Valentino en Buenos Aires fue menor que en el resto del mundo. El éxito fue ambiguo porque, por un lado, los argentinos celebraron el reconocimiento internacional de su baile más popular pero, por otro, la imagen de un Valentino de piel oscura como el estereotipo del país molestó. Durante las primeras décadas del siglo XX, Buenos Aires, una ciudad inmigratoria, estaba llena de inmigrantes, especialmente italianos del sur de la península, como Valentino, y esa identificación resultaba complicada.

Aunque en Argentina se criticará ese tango “internacional”, será el tango que se imponga. Por eso Valentino resulta, en la escena de Ingram, un ensamblaje

\footnotetext{
${ }^{12}$ En las fotos más emblemáticas de Carlos Gardel, él aparece también vestido de gaucho. Gardel, que antes de morir, estaba consolidando su carrera en el cine americano, filmó varias películas en los años 30, casi todas en los estudios de Paramount, en Long Island. La única película que filmó en Hollywood fue The big broadcast en 1936 [Cazadores de estrellas].
} 
de tradiciones en donde el vestido gaucho se mezcla con el sombrero urbano, el tango se baila con piruetas nuevas en un sótano urbano pero en un escenario con decoración campesina. La escena parece haber tenido su efecto, precisamente, por el ensamblaje que logra crear. Ingram puede haber tenido asesores argentinos, profesores expertos de tango, pero el cine tiene sus propias leyes. En el estudio se crea la imagen de un latin lover que bailará el tango transnacional y global. Julio Desnoyers (nieto de español e hijo de francés) también será el ensamblaje racializado de un hispanismo de piel oscura en el cuerpo de un italiano del sur, actuando un personaje argentino. Giorgio Bertellini estudió las razones de la atracción de ese cuerpo, en sus diferentes roles:

In the increasingly racialized industry of desire fostered by Hollywood, the lover Valentino could convey the sense of both an emotional and romantic connection with audiences while transmuting his Italianness into a universal (white) characteristic of humanity larger than the sum of the roles he played as an Arab sheik, a Spanish torero, and an Argentine tango pirate. (Bertellini 48)

Esa conexión generó la representación de un exotismo tradicional que borró sus marcas detrás del rostro seductor de Valentino. Y que seguirá produciendo nuevas identidades de lo hispano en la escena global que la industria del cine instaló a principios del siglo XX. Son los territorios portátiles de la ficción, que se seguirán reproduciendo independientemente de sus referentes. Como dije, Los Angeles fue la tercera parte de un triángulo transnacional. Podemos hipotetizar que las comunidades hispanas aprendieron que las identidades son siempre una negociación. Pero no se trata de una negociación entre pares sino que se basa en disimetrías y desigualdades. La cultura es una permanente transacción entre múltiples prácticas y políticas de la representación. El caso de Los cuatro jinetes del Apocalipsis muestra cómo las prácticas globales 
necesitan ser consagradas. Ese fue el caso de Los Angeles en el cruce de diversas tradiciones culturales y de la moderna práctica de la cultura en el mercado.

\section{Bibliografía}

Barton, Ruth. Rex Ingram: Visionary Director of the Silent Screen. Kentucky: University of Kentucky Press, 2014.

Bertellini, Giorgio. "The Atlantic Valentino. "The Inimitable Lover" as Racialized and Gendered Italian.” In Loretta Baldassar and Donna R. Gabaccia. Inmimacy and Italian Migration. Gender and Domestic Lives in a Mobile World. New York: Fordham University Press, 2011.

Blasco Ibáñez, Vicente. El militarismo mexicano. Valencia: Prometeo, 1920. . Artículos sobre México. México: Talleres linotipográficos de "El Hogar," 1920. Prólogo de Enrique de Llano. . Los cuatro jinetes del Apocalipsis. Barcelona: Planeta, 1958. . La reina Calafia. Valencia: Prometeo, 1923.

Canaro, Francisco. Mis memorias. Mis bodas de oro con el tango. Buenos Aires: Corregidor, 1999.

Corbix, John. "An Epic of the Movies.” New York Times, March 27, 1921.

García Jiménez, Francisco. Estampas de tango. Buenos Aires: Rodolfo Alonso Editor, 1968.

Gascó Contell, Emilio. Genio y figura de Blasco Ibáñez: agitador, aventurero y novelista. Madrid: Afrodisio Aguado S.A. Editores y Libreros, 1957.

Pujol, Sergio. Valentino en Buenos Aires. Los años veinte y el espectáculo. Buenos Aires: Emecé, 1994.

Reig, Ramiro. Vicente Blasco Ibáñez. Madrid: Espasa, 2002. 
CATEDRAL TOMADA: Revista literaria latinoamericana / Journal of Latin American Literary Criticism Graciela Montaldo

Tompkins, Cynthia. "El último malón de Alcides Greca: Repetición y cine de atracciones”. In Studies in Latin American Popular Culture. 32, 2014.

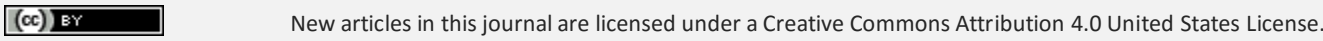

